\title{
Regulatory/Effector T-Cell Ratio Is Reduced in Coronary Artery Disease
}

\author{
Takuo Emoto, MD; Naoto Sasaki, MD, PhD; Tomoya Yamashita, MD, PhD; \\ Kazuyuki Kasahara, MD; Keiko Yodoi, MD; Yoshihiro Sasaki, MD; \\ Takuya Matsumoto, MD; Taiji Mizoguchi, MD; Ken-ichi Hirata, MD, PhD
}

\begin{abstract}
Background: The protective function of regulatory T cells ( $\left.T_{r e g}\right)$ has been identified in experimental atherosclerosis, but the contribution of $T_{\text {reg }}$ to the pathogenesis of human coronary artery disease (CAD) remains poorly understood. We investigated $T_{\text {reg }}$ and regulatory $\mathrm{T}$-cell/effector $\mathrm{T}$-cell $\left(\mathrm{T}_{\mathrm{reg}} / \mathrm{T}_{\mathrm{eff}}\right)$ ratio in peripheral blood samples from CAD patients using a new strategy for precise identification of $T_{\text {reg. }}$

Methods and Results: Peripheral blood samples were collected from 73 stable CAD patients (55 middle-aged CAD patients and 18 old CAD patients) and 64 controls ( 47 middle-aged controls and 17 young controls). $C D 3^{+}{ }^{C D} 4^{+}+{ }^{+}+3^{+}$ T cells were divided into 3 fractions: CD45RA+FoxP3low resting Treg (Fr1), CD45RA-FoxP3 ${ }^{\text {high }}$ activated Treg (Fr2), and CD45RA-FoxP3 low non-Treg (Fr3). CAD patients had lower percentages of Fr1 and Fr2 and higher percentages of Fr3 and CD45RA-Foxp3- $\mathrm{T}_{\text {eff }}(\mathrm{Fr} 4+5)$ within the $\mathrm{CD}^{+}{ }^{+} \mathrm{CD} 4+{ }^{+} \mathrm{T}$-cell population compared to age-matched controls. $\mathrm{T}_{\text {reg }} / \mathrm{T}_{\text {eff }}$ ratio $(\mathrm{Fr} 1+2 / \mathrm{Fr} 3+4+5)$ in $\mathrm{CAD}$ patients was also markedly lower than in controls (middle-aged control, $0.17 \pm 0.09$ vs. middle-aged $C A D, 0.10 \pm 0.05 ; P<0.001)$. The percentage of $C D 4+C D 28$ null $T$ cells within the $C D 4+T-c e l l$ population was negatively correlated with $T_{\text {reg }} / T_{\text {eff }}$ ratio, excluding $C D 4+C D 28$ null $T$ cells $<0.3 \%(r=-0.27, P<0.05)$. High-sensitivity C-reactive protein was also negatively correlated with $T_{\text {reg }} / T_{\text {eff }}$ ratio $(r=-0.22, P<0.05)$.
\end{abstract}

Conclusions: $C A D$ patients had reduced $\mathrm{T}_{\text {reg }}$ and $\mathrm{T}_{\text {reg }} / \mathrm{T}_{\text {eff }}$ ratio compared to healthy controls. The present findings may be helpful when developing immunotherapy for the prevention of CAD. (Circ J 2014; 78: 2935-2941)

Key Words: Coronary artery disease; Immune system; Regulatory T cell

C oronary artery disease $(\mathrm{CAD})$ is one of the life-threatening manifestations of atherosclerosis in humans. It is now widely accepted that vascular wall inflammation is an important hallmark of atherosclerosis and contributes to severe clinical events including acute coronary syndrome (ACS) and stroke. ${ }^{1-3}$ It is well known that in addition to innate immunity, adaptive immunity involving T-cell-mediated pathogenic immune response plays an important role in the inflammatory process during atherogenesis in humans and mice., 4,5 Thus, therapeutic interventions targeting the inflammatory response in atherogenesis represent a promising therapeutic strategy to improve cardiovascular outcome.

\section{Editorial $\mathrm{p} 2843$}

Recent studies in mice have shown that among CD4 ${ }^{+} \mathrm{T}$-cell subsets, regulatory T cells ( $\mathrm{T}_{\text {reg }}$ ) expressing CD25 (interleukin [IL]-2 receptor $\alpha$-chain) molecule and the transcription factor
FoxP3 (forkhead box P3), play a protective role in atherogenesis by dampening pathogenic effector $T$ cell (Teff) response. ${ }^{6-10}$ We believe that the balance between $\mathrm{T}_{\text {eff }}$ and $\mathrm{T}_{\text {reg }}$ is important for the control of atherosclerotic disease, ${ }^{11}$ and that increasing the $\mathrm{T}_{\mathrm{reg}} / \mathrm{T}_{\text {eff }}$ ratio, by suppressing $\mathrm{T}_{\text {eff }}$ response and promoting $\mathrm{T}_{\text {reg }}$ response, could be a promising therapeutic approach for atherosclerotic disease. ${ }^{12}$

Although there is much experimental evidence supporting a protective role for $\mathrm{T}_{\text {reg }}$ in atherogenesis, understanding of their clinical importance is still lacking. Some studies investigated the correlation between circulating $T_{\text {reg level and CAD }}$ to clarify whether impaired function or reduced numbers of Treg may contribute to the progression of atherosclerotic diseases in humans, but the results are still controversial. ${ }^{13-15}$ Discrepancy among previous reports with regards to the association between circulating $\mathrm{T}_{\text {reg }}$ level and CAD may potentially be due to the difference in immune system between humans and mice, or limitations in methodology. The transcription

Received June 8, 2014; revised manuscript received September 11, 2014; accepted September 16, 2014; released online October 18,2014

Time for primary review: 24 days

Division of Cardiovascular Medicine, Department of Internal Medicine, Kobe University Graduate School of Medicine, Kobe, Japan

Clinical Trial Registration Information: [URL] http://www.umin.ac.jp/ctr/ Unique identifier: UMIN000012049

Mailing address: Naoto Sasaki, MD, PhD, Division of Cardiovascular Medicine, Department of Internal Medicine, Kobe University

Graduate School of Medicine, 7-5-1 Kusunoki-cho, Chuo-ku, Kobe 650-0017, Japan. E-mail: sasakin@med.kobe-u.ac.jp

ISSN-1346-9843 doi:10.1253/circj.CJ-14-0644

All rights are reserved to the Japanese Circulation Society. For permissions, please e-mail: cj@j-circ.or.jp 

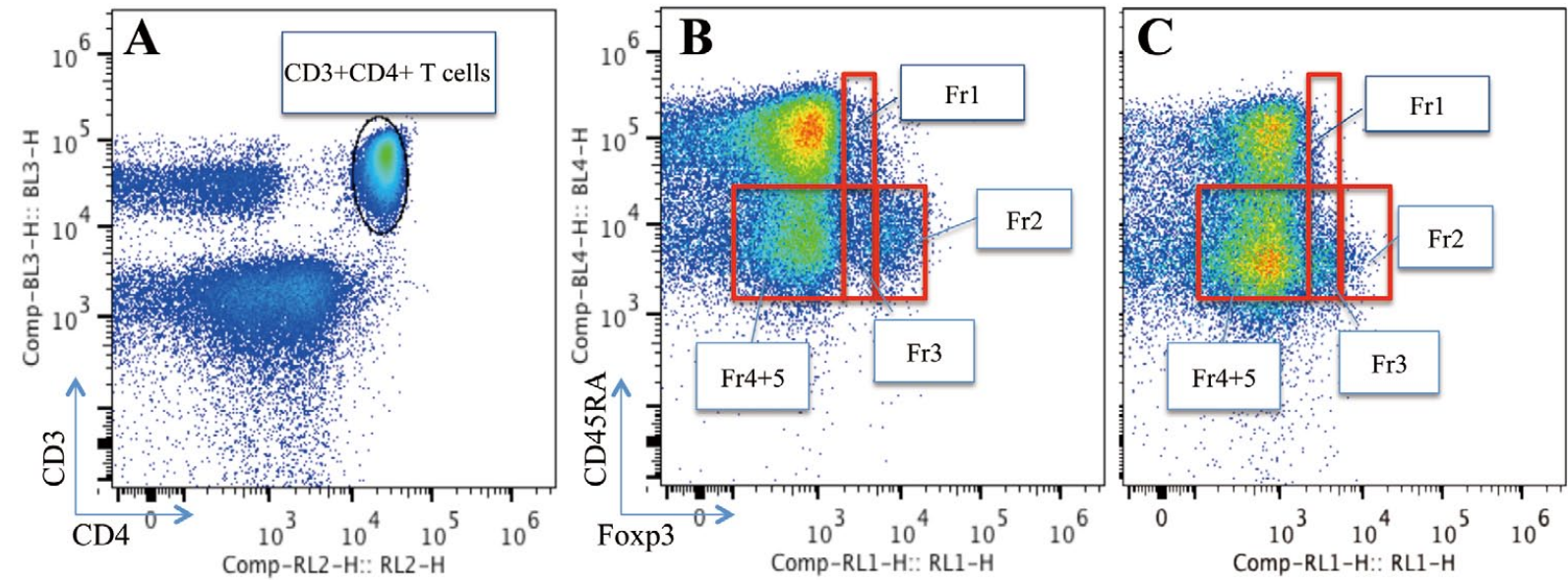

Figure 1. Representative fluorescence-activated cell sorter analysis of T cells. (A) Flow cytometry of the expression of CD45RA and FoxP3 in $\mathrm{CD}^{+}{ }^{+} \mathrm{CD} 4{ }^{+} \mathrm{T}$ cells from (B) the middle-aged control group and (C) the middle-aged coronary artery disease group. Fr1, CD45RA+FoxP3low resting Treg; Fr2, CD45RA-FoxP3high activated Treg; Fr3, CD45RA-FoxP3low non-Treg; Fr4+5, CD45RA-FoxP3- nonTreg. Teff, effector T cell; Treg, regulatory T cell.
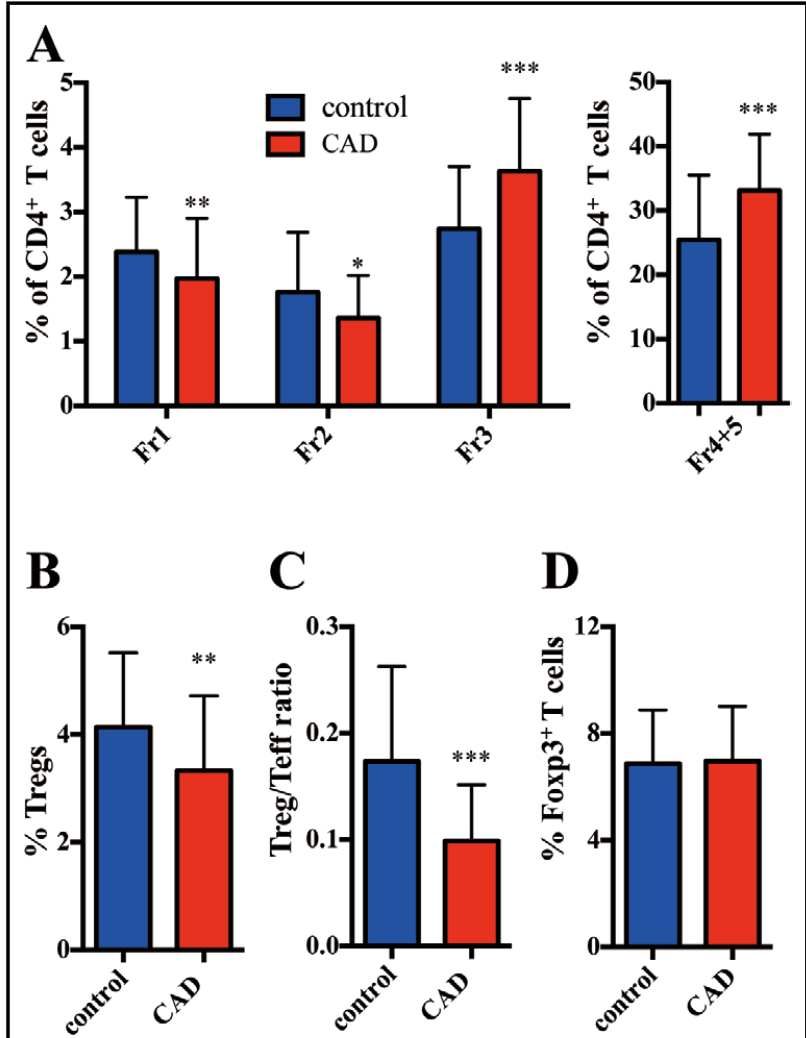
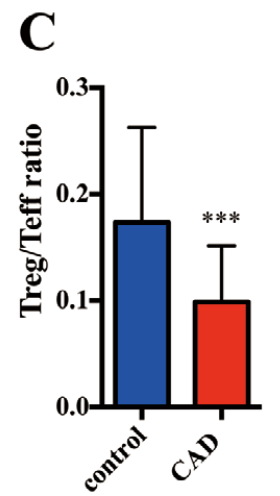
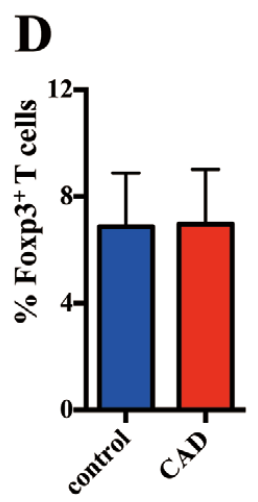

Figure 2. Comparison of T-cell subsets between the agematched control and coronary artery disease (CAD) groups. (A) T-cell fractions; (B) regulatory T cells (Treg; defined as Fr1+Fr2) \% of CD4+ T cells; $($ C) regulatory T-cell/effector T-cell ( Treg $/ \mathrm{T}_{\text {eff }}$ ) ratio (Fr1+2/Fr3+4+5); (D) FoxP3 ${ }^{+} \mathrm{T}$ cells (defined as Fr $1+2+3) \%$ of $\mathrm{CD} 4+\mathrm{T}$ cells. ${ }^{\star} \mathrm{P}<0.05$, ${ }^{\star \star} \mathrm{P}<0.01,{ }^{* \star *} \mathrm{P}<0.001$ (middle-aged control and CAD groups; Mann-Whitney U-test or Student's t-test). factor FoxP3 is the master regulator and the most reliable molecular marker for $\mathrm{T}_{\text {reg }}$ at least in mice. ${ }^{16}$ Miyara et al, however, showed that human $\mathrm{CD} 4{ }^{+} \mathrm{FoxP} 3^{+} \mathrm{T}$ cells are heterogeneous in function by separating FoxP $3^{+}$cells into 3 subsets based on the expression of FoxP3 and CD45RA. ${ }^{17}$ Thus, further precise clarification for the role of $\mathrm{T}_{\text {reg }}$ in atherosclerotic diseases is needed using this method.

In the present study, we compared $T_{\text {reg level in the control }}$ group with that in the CAD group by separating CD4+FoxP3- $\mathrm{T}$ cells into 3 functionally and phenotypically different subpopulations based on the expression of FoxP3 and CD45RA. Given that $\mathrm{CD} 4{ }^{+} \mathrm{CD} 28^{\text {null }} \mathrm{T}$ cells have been reported to promote atherosclerosis and plaque vulnerability, ${ }^{18,19}$ we also examined the correlation between these cells and $\mathrm{T}_{\text {reg. }}$. We for the first time identified an imbalance between $\mathrm{T}_{\mathrm{reg}}$ and $\mathrm{T}_{\text {eff }}$ and a negative correlation between $\mathrm{CD} 4{ }^{+} \mathrm{CD} 28^{\text {null }} \mathrm{T}$ cells and the $\mathrm{T}_{\text {reg }} / \mathrm{T}_{\text {eff }}$ ratio in $\mathrm{CAD}$ patients, suggesting the clinical importance of $\mathrm{T}_{\text {reg }}$ for the prevention of atherosclerotic diseases.

\section{Methods}

\section{Subjects}

Sixty-four patients with CAD were recruited from Kobe University Hospital. We included only stable angina pectoris (AP) and old myocardial infarction (MI) patients who had undergone percutaneous coronary intervention or coronary artery bypass graft surgery $\geq 6$ months earlier; ACS patients were excluded. Patients with systemic disease including hepatic disease, renal disease (serum creatinine $>2.0 \mathrm{mg} / \mathrm{dl}$ ), collagen disease and malignancy were also excluded. Blood samples were collected after overnight fast.

Sixty-four controls without cardiovascular health problems were recruited as an age- and gender-matched control group from a health medical center, Kenko Life Plaza, Hyogo Health Service Association. Blood samples were also collected after overnight fast. The criteria for inclusion in the control group were no history of vascular disease, hypertension, diabetes, or treatment for dyslipidemia. No history of vascular disease was defined as no documented vascular disease, symptoms of AP, 

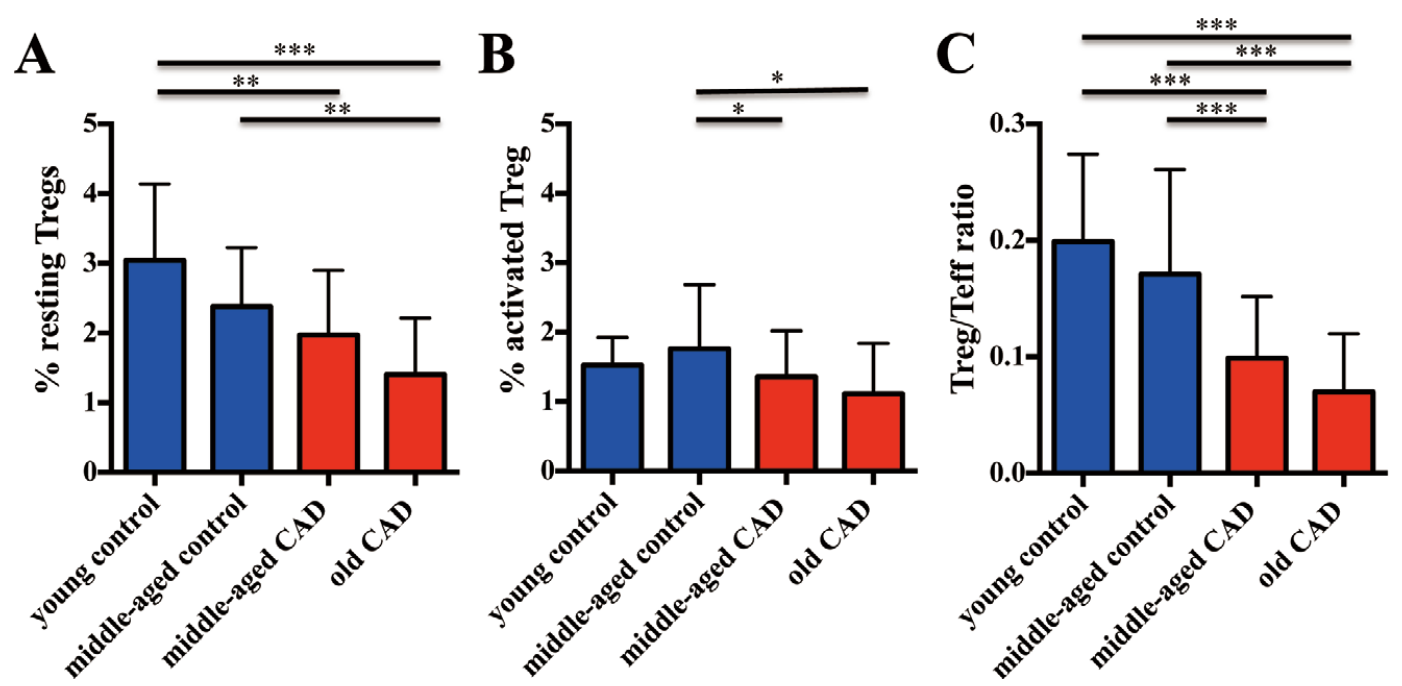

Figure 3. Age-related distribution of regulatory T cells (Treg). (A) Resting Treg (Fr1); (B) activated Treg (Fr2); (C) regulatory T-cell/ effector $T$-cell $\left(T_{\text {reg }} / T_{\text {eff }}\right.$ ) ratio. ${ }^{*} P<0.05$, ${ }^{*} P<0.01$, ${ }^{* \star *} P<0.001$ (young control, middle-aged control, middle-aged $C A D$ and old $C A D$ groups; 1-way ANOVA test followed by Tukey's post-hoc analysis). CAD, coronary artery disease.
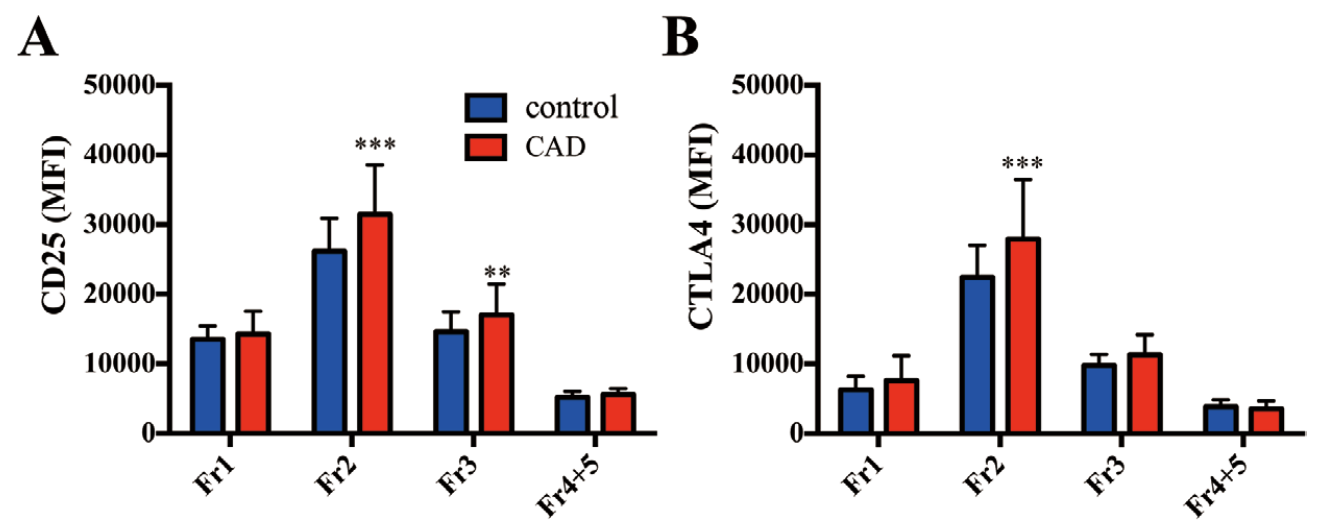

Figure 4. Expression of suppression molecules was increased in activated regulatory T cells (Treg; Fr2). (A) CD25 and (B) CTLA4 expression of each fraction. ${ }^{\star} \mathrm{P}<0.05,{ }^{\star \star} \mathrm{P}<0.01$, ${ }^{\star \star \star} \mathrm{P}<0.001$ (middle-aged control and CAD groups; Mann-Whitney U-test). CAD, coronary artery disease.

abnormality on electrocardiogram indicating old MI or AP, or abnormality on chest X-ray. Hypertension was defined as blood pressure $>140 / 90 \mathrm{mmHg}$ or use of anti-hypertensive drugs. Diabetes was defined as HbA1c $>6.5 \%$ (National Glycohemoglobin Standardization Program), use of oral anti-diabetic drugs or insulin. Although they had not been treated, 24 controls with dyslipidemia (low-density lipoprotein cholesterol [LDLC] $>140 \mathrm{mg} / \mathrm{dl}$ or triglycerides $>150 \mathrm{mg} / \mathrm{dl}$ ) were included in this control group. We divided the control and $\mathrm{CAD}$ groups into 2 groups each: young control group $<50$ years old, middle-aged control group $\geq 50$ years old, middle-aged CAD group $\leq 70$ years old (middle-aged CAD) and old CAD group $>70$ years old (old CAD).

This study was approved by the Ethics Committee of Kobe University (No. 1318) and Kenko Life Plaza, Hyogo Health Service Association. All subjects provided oral and written in- formed consent to participate in this study.

\section{Flow Cytometry}

Human peripheral blood mononuclear cells of CAD patients and healthy volunteers were obtained in EDTA-coated tubes and prepared by Ficoll gradient centrifugation. Cells were stained in phosphate-buffered saline containing $2 \%$ fetal calf serum. Fluorescence-activated cell sorter analysis (Figure 1) was done using an Attune Acoustic Focusing Cytometer (Life Technologies, Carlsbad, CA, USA) using FlowJo10.0.6 software (Tree Star). The antibodies used were as follows: PerCPCy5.5-anti-CD3 (clone SK7; BD Biosciences), APCCy7anti-CD4 (clone RPA-T4; BD Biosciences), FITC-antiCD25 (clone MA251; BD Biosciences), PE-anti-CD28 (clone CD28.2; BD Biosciences), APC-anti-FoxP3 (clone 236A/E7; BD Biosciences), PE-anti-CTLA4 (clone BNI3; BD Biosci- 


\begin{tabular}{|c|c|c|c|c|}
\hline & $\begin{array}{l}\text { Young control } \\
\qquad(n=18)\end{array}$ & $\begin{array}{l}\text { Middle-aged } \\
\text { control }(n=49)\end{array}$ & $\begin{array}{l}\text { Middle-aged } \\
\text { CAD }(n=55)\end{array}$ & $\begin{array}{l}\text { Old CAD } \\
(n=18)\end{array}$ \\
\hline \multicolumn{5}{|l|}{ Characteristics } \\
\hline Age (years) & $45.7 \pm 2.43^{\star \star \star}$ & $59.2 \pm 6.0$ & $60.3 \pm 8.2$ & $73.5 \pm 2.4^{\star \star \star}$ \\
\hline Sex (\% male) & 72 & 84 & 91 & 83 \\
\hline $\mathrm{BMI}\left(\mathrm{kg} / \mathrm{m}^{2}\right)$ & $24.4 \pm 4.2$ & $22.4 \pm 2.7$ & $26.3 \pm 4.2^{\star \star \star}$ & $24.8 \pm 8.2$ \\
\hline Smoking & $78^{*}$ & 48 & $77^{\star *}$ & $82^{*}$ \\
\hline Dyslipidemia $^{\dagger}$ & 22 & 18 & $89^{* \star *}$ & $78^{* * *}$ \\
\hline Hypertension $\ddagger$ & 0 & 2 & $89^{\star \star \star}$ & $83^{\star \star \star}$ \\
\hline Diabetes§ & 0 & 0 & $44^{\star \star \star}$ & $44^{\star * \star}$ \\
\hline \multicolumn{5}{|l|}{ No. coronary vessels" } \\
\hline 1-vessel disease & & & 29 & 33 \\
\hline 2-vessel disease & & & 42 & 28 \\
\hline 3-vessel disease & & & 29 & 39 \\
\hline \multicolumn{5}{|l|}{ Medications } \\
\hline Anti-diabetes drug (including insulin) & 0 & 0 & 44 & 50 \\
\hline Statins & 0 & 0 & 91 & 72 \\
\hline ACEI/ARB & 0 & 0 & 69 & 67 \\
\hline$\beta$-blocker & 0 & 0 & 60 & 61 \\
\hline Ca blocker & 0 & 0 & 69 & 50 \\
\hline \multicolumn{5}{|l|}{ Laboratory data } \\
\hline AST (U/L) & $22.8 \pm 8.87$ & $19.8 \pm 5.1$ & $24.3 \pm 11.4$ & $24.1 \pm 8.2$ \\
\hline ALT (U/L) & $30.0 \pm 24.2$ & $19.5 \pm 10.3$ & $26.7 \pm 18.2$ & $21.8 \pm 9.4$ \\
\hline BUN (mg/dl) & $12.1 \pm 2.35$ & $13.8 \pm 2.67$ & $17.3 \pm 5.2^{\star \star \star}$ & $17.4 \pm 4.7^{\star}$ \\
\hline $\mathrm{Cr}(\mathrm{mg} / \mathrm{dl})$ & $0.72 \pm 0.15$ & $0.80 \pm 0.14$ & $0.97 \pm 0.27^{\star \star \star}$ & $0.92 \pm 0.25$ \\
\hline HDL-C (mg/dl) & $57.8 \pm 15.6$ & $73.8 \pm 32.4$ & $46.5 \pm 14.7^{* * *}$ & $46.9 \pm 11.4^{\star \star \star}$ \\
\hline LDL-C (mg/dl) & $114.9 \pm 31.8$ & $112.5 \pm 31.9$ & $93.6 \pm 30.5^{*}$ & $91.6 \pm 26.2$ \\
\hline TG (mg/dl) & $142 \pm 98^{*}$ & $102 \pm 71$ & $200 \pm 110^{\star * \star}$ & $126 \pm 113$ \\
\hline HbA1c (NGSP\%) & $5.29 \pm 0.52$ & $5.44 \pm 0.30$ & $6.41 \pm 1.23^{\star \star \star}$ & $6.17 \pm 0.62^{*}$ \\
\hline hsCRP (mg/dl) & $0.07 \pm 0.12$ & $0.08 \pm 0.14$ & $0.09 \pm 0.11$ & $0.21 \pm 0.24^{*}$ \\
\hline
\end{tabular}

Data given as mean \pm SD or $\%$. ${ }^{*} \mathrm{P}<0.05,{ }^{\star \star} \mathrm{P}<0.01$, ${ }^{* \star *} \mathrm{P}<0.001$ (1-way ANOVA test followed by Tukey's post-hoc analysis; natural logarithmic transformation used for comparison of TG and hs-CRP). +LDL-C >140 mg/dl, TG

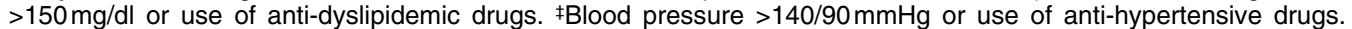
\$HbA1c $>6.5 \%$ (NGSP), use of oral anti-diabetic drugs, or insulin. INo. major coronary vessels with $>75 \%$ stenosis on diagnostic coronary angiography and requiring treatment. ACEI, angiotensin-converting enzyme inhibitor; ALT, alanine aminotransferase; ARB, angiotensin receptor blocker; AST, aspartate aminotransferase; BMI, body mass index; BUN, blood urea nitrogen; CAD, coronary artery disease; HDL-C, high-density lipoprotein cholesterol; hsCRP, high-sensitivity C-reactive protein; LDL-C, low-density lipoprotein cholesterol; TG, triglycerides.

ences), PECy7-anti-CD45RA (clone L48; BD Biosciences) and isotype-matched control antibodies.

\section{Statistical Analysis}

Data are given as mean \pm SD. Mann-Whitney U-test or Student's t-test, or Fisher's exact test were used for statistical comparison between 2 groups (Figure 2). One-way and 2-way ANOVA followed by Tukey's post-hoc analysis was used for statistical comparison between 4 groups (Figures 3,4; Table).

Pearson's correlation analysis was used for statistical correlation between 2 parameters (Figures 5,6). All statistical analysis was 2 -sided, with $\mathrm{P}<0.05$ considered statistically significant. For statistical analysis, GraphPad Prism version 6.0 (GraphPad Software, San Diego, CA, USA) was used.

\section{Results}

The baseline characteristics, medications and laboratory data of the CAD and control groups are listed in Table. The CAD group had relatively low LDL-C because most of these patients took statins. High-density lipoprotein cholesterol was lower, and triglycerides and $\mathrm{HbA} 1 \mathrm{c}$ were higher in the middleaged CAD group compared to age-matched controls (Table).

Based on the expression of FoxP3 and CD45RA, we separated the T-cell subpopulations into fractions (Fr1, Fr2, Fr3 and Fr4+5; Figure 1) on flow cytometry. Representative analyses of each T-cell fraction from the control and CAD groups are shown in Figures 1B,C. In accordance with a previous report, human $\mathrm{T}_{\text {reg }}$ were divided into $\mathrm{CD} 45 \mathrm{RA}{ }^{+} \mathrm{FoxP} 3^{\text {low }}$ resting $\mathrm{T}_{\text {reg }}$ (Fr1) and CD45RA-FoxP3 ${ }^{\text {high }}$ activated $\mathrm{T}_{\text {reg }}$ (Fr2), and activated $T_{\text {eff }}$ were defined as CD45RA-FoxP3 ${ }^{\text {low }} \mathrm{T}$ cells $(\mathrm{Fr} 3)$ and CD45RA-FoxP3- $\mathrm{T}$ cells (Fr4+5). The middle-aged CAD group had a lower percentage of resting $\mathrm{T}_{\text {reg }}(2.38 \pm 0.84 \%$ in the control vs. $1.97 \pm 0.93 \%$ in the CAD group, $\mathrm{P}<0.01)$ and activated $\mathrm{T}_{\text {reg }}(1.76 \pm 0.93 \%$ in the control vs. $1.36 \pm 0.66 \%$ in the $\mathrm{CAD}$ group, $\mathrm{P}<0.05)$ and a higher percentage of $\mathrm{Fr} 3(2.74 \pm 0.96 \%$ in the control vs. $3.63 \pm 1.13 \%$ in the CAD group, $\mathrm{P}<0.001$ ) and Fr4+5 (25.3 $\pm 10.2 \%$ in the control group, $33.1 \pm 8.8 \%$ in the $\mathrm{CAD}$ group, $\mathrm{P}<0.001)$ within the $\mathrm{CD}^{+} \mathrm{T}$ cell population compared to the middle-aged control group (Figure 2A). The percentage of $\mathrm{T}_{\text {reg }}$ fractions including $\mathrm{Fr} 1+\mathrm{Fr} 2$ was significantly decreased in the middle-aged CAD group compared to the 


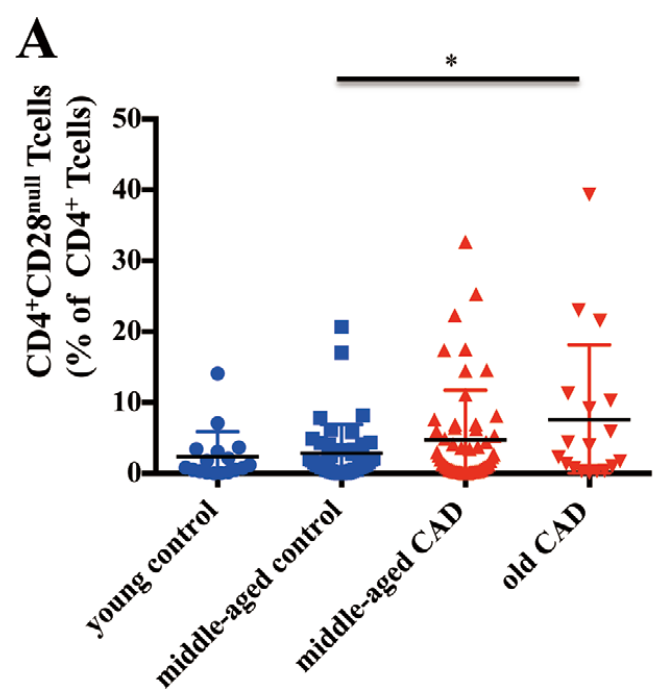

\section{B}

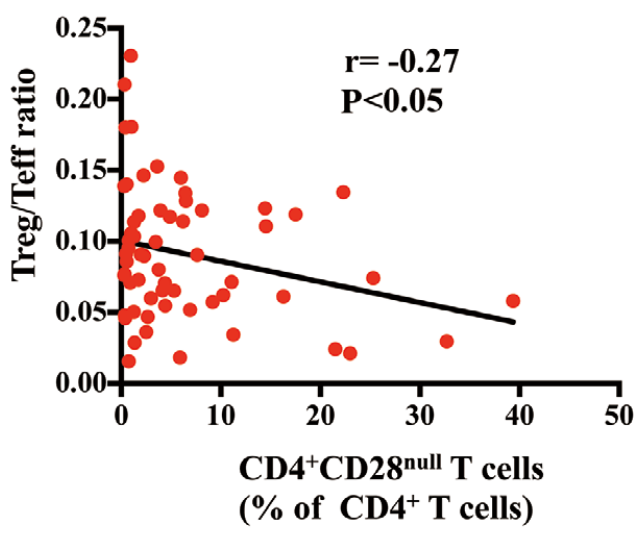

Figure 5. Population of $C D 4+C D 28$ null $T$ cell was inversely correlated with regulatory $T$-cell/effector $T$-cell $\left(T_{\text {reg }} / T_{\text {eff }}\right)$ ratio. (A) CD4+CD28null T cell level (1-way ANOVA test followed by Tukey's post-hoc analysis); (B) correlation between $\mathrm{T}_{\text {reg }} / \mathrm{T}_{\text {eff }}$ ratio and \% of $\mathrm{CD} 4{ }^{+} \mathrm{CD} 28$ null $\mathrm{T}$ cells in the CD4+ $\mathrm{T}$ cells in all coronary artery disease (CAD) patients (middle-aged and old CAD groups), excluding \% of $\mathrm{CD} 4{ }^{+} \mathrm{CD} 28$ null $T$ cells $<0.3 \%$ in all CAD patients, calculated by Pearson's correlation. ${ }^{*} \mathrm{P}<0.05$.

middle-aged control group (Figure $2 \mathrm{~B}$ ). The $\mathrm{T}_{\mathrm{reg}} / \mathrm{T}_{\mathrm{eff}}$ ratio (Fr1+2/Fr3+4+5) in middle-aged CAD group (0.10 \pm 0.05$)$ was markedly lower than in the middle-aged control group $(0.17 \pm$ $0.09, \mathrm{P}<0.001$; Figure 2C), indicating the imbalance between $\mathrm{T}_{\text {reg }}$ and $\mathrm{T}_{\text {eff }}$ under atherosclerotic conditions. Notably, we found no difference in FoxP3 ${ }^{+} \mathrm{T}$ cell level including Fr1+Fr2+Fr3 between the middle-aged CAD and middle-aged control groups (Figure 2D).

Consistent with a previous report, ${ }^{17}$ the proportion of resting $\mathrm{T}_{\mathrm{reg}}(\mathrm{Fr} 1)$ was decreased in the young control group compared to the middle-aged control group, whereas that of activated $\mathrm{T}_{\text {reg }}(\mathrm{Fr} 2)$ was increased (Figures 3A,B). Notably, both fractions tended to be decreased in CAD patients. In addition, the $\mathrm{T}_{\text {reg}} / \mathrm{T}_{\text {eff }}$ ratio tended to decrease with aging in both the $\mathrm{CAD}$ and control groups (Figure 3C).

Next, the effects of CAD on the expression of $\mathrm{T}_{\text {reg-associated }}$ molecules such as CD25 and cytotoxic T lymphocyte-associated protein 4 (CTLA-4) were determined in each T-cell fraction on flow cytometry. Notably, CD45RA-FoxP3 ${ }^{\text {high }}$ activated $\mathrm{T}_{\text {reg }}(\mathrm{Fr} 2)$ and CD45RA-FoxP3 ${ }^{\text {low }}$ non- $\mathrm{T}_{\text {reg }}(\mathrm{Fr} 3)$ from the CAD group expressed higher levels of these molecules compared to those from the control group (Figure 4), implying an activated phenotype of $\mathrm{T}_{\text {reg }}$ and $\mathrm{T}_{\text {eff }}$ in the presence of CAD.

Recent studies have shown that the percentage of CD4 ${ }^{+} \mathrm{CD} 28^{\text {null }}$ $\mathrm{T}$ cells is increased in patients with ACS, which may contribute to plaque instability. ${ }^{18,19} \mathrm{CD} 4{ }^{+} \mathrm{CD} 28^{\text {null }} \mathrm{T}$ cells tended to be increased in the CAD group compared to the control group (Figure 5A). We investigated the association between $\mathrm{CD} 4{ }^{+} \mathrm{CD} 28^{\text {null }} \mathrm{T}$ cells and $\mathrm{T}_{\text {reg }}$ and found that $\mathrm{CD} 4{ }^{+} \mathrm{CD} 28^{\text {null }} \mathrm{T}$ cells were detected mainly in Fr4 or Fr5 Teff populations, but not in Fr1 or Fr2 Treg populations (data not shown). Interestingly, we observed an inverse correlation between $\mathrm{CD} 4{ }^{+} \mathrm{CD} 28^{\text {null }} \mathrm{T}$ cells and the $\mathrm{T}_{\text {reg}} / \mathrm{T}_{\text {eff }}$ ratio in all CAD patients (middle-aged and old CAD groups), when we excluded the population of $\mathrm{CD} 4{ }^{+} \mathrm{CD} 28^{\text {null }} \mathrm{T}$ cells $<0.3 \%$ of $\mathrm{CD}^{+}{ }^{+} \mathrm{T}$ cells (Figure $5 \mathrm{~B}$ ), although we found no significant correlation in the whole population of these cells. This suggests that the $\mathrm{T}_{\mathrm{reg}} / \mathrm{T}_{\mathrm{eff}}$ balance

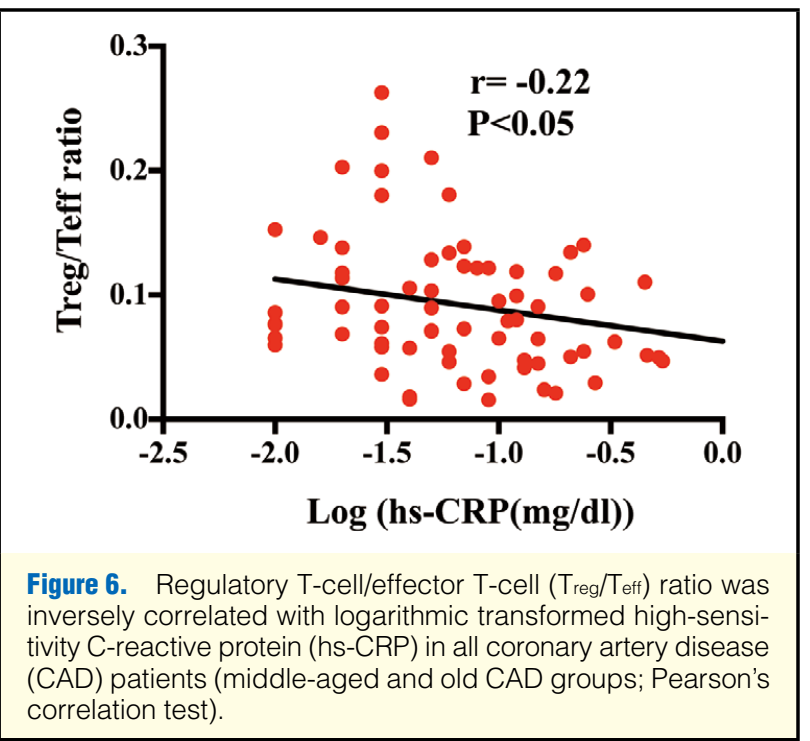

may modulate expansion but not generation of $\mathrm{CD} 4{ }^{+} \mathrm{CD} 28^{\text {null }}$ $\mathrm{T}$ cells through mechanisms that remain undefined.

Finally, a negative correlation was observed between $\mathrm{T}_{\mathrm{reg}} / \mathrm{T}_{\mathrm{eff}}$ ratio and serum high-sensitivity $\mathrm{C}$-reactive protein (hs-CRP) level (Figure 6).

\section{Discussion}

Several papers investigated the association between $\mathrm{T}_{\text {reg level }}$ in peripheral blood and atherosclerotic disease, but reported conflicting data possibly due to different methods of defining $\mathrm{T}_{\text {reg. }}$ In the present study, we precisely defined $\mathrm{T}_{\text {reg }}$ and $\mathrm{T}_{\text {eff }}$ on flow cytometry and compared $\mathrm{T}_{\text {reg }}$ and $\mathrm{T}_{\mathrm{reg}} / \mathrm{T}_{\text {eff }}$ ratio in the peripheral blood from CAD patients with those from controls. 
We also examined the correlation between $\mathrm{CD} 4{ }^{+} \mathrm{CD} 28^{\text {null }} \mathrm{T}$ cells, which may contribute to atherosclerosis development and plaque vulnerability, and $\mathrm{T}_{\text {reg. }}$. We have clearly showed a decreased $\mathrm{T}_{\text {reg }} / \mathrm{T}_{\text {eff }}$ ratio and a negative correlation between CD4 ${ }^{+} \mathrm{CD} 28^{\text {null }} \mathrm{T}$ cells and the $\mathrm{T}_{\mathrm{reg}} / \mathrm{T}_{\text {eff }}$ ratio in $\mathrm{CAD}$ patients, suggesting that reduced $\mathrm{T}_{\text {reg }}$ may contribute to the progression of atherosclerotic disease in humans.

Based on the strong evidence supporting a protective role for $\mathrm{T}_{\mathrm{reg}}$ in experimental atherosclerosis, ${ }^{11}$ several studies explored the role of $\mathrm{T}_{\text {reg }}$ in clinical atherosclerosis. ${ }^{13-15,20} \mathrm{Wigren}$ et al defined $\mathrm{T}_{\text {reg }}$ as $\mathrm{CD}^{+}{ }^{+} \mathrm{FoxP}^{+}$or $\mathrm{CD}^{+}{ }^{+} \mathrm{CD} 25^{+} \mathrm{FoxP} 3^{+}$cells and showed that there was an association between low baseline $\mathrm{CD}^{+}{ }^{+} \mathrm{FoxP}^{+} \mathrm{T}$ cells and an increased risk for the development of acute coronary events but not stroke. ${ }^{15}$ Their study was the first large-volume and long follow-up study investigating the association between circulating $\mathrm{T}_{\text {reg }}$, defined as the expression of FoxP3 in CD4 ${ }^{+} \mathrm{T}$ cells, and $\mathrm{CAD}$, and suggests that $\mathrm{T}_{\text {reg }}$ may play a protective role in human atherosclerosis and therefore are of potential clinical importance. Although the staining method using the Foxp3 molecule can discriminate between $\mathrm{T}_{\text {reg }}$ and $\mathrm{T}_{\text {eff }}$ more precisely than that using the combination of CD25 and CD127 molecules, it is possible that such a population may still include some Teff.

A recent paper showed that the combination of FoxP3 and CD45RA staining of CD4+ $\mathrm{T}$ cells in peripheral blood lymphocytes can identify $T_{\text {reg }}$ more precisely than previous methods. ${ }^{17}$ Using this staining method, human Treg were divided into CD45RA+FoxP3 ${ }^{\text {low }}$ resting $\mathrm{T}_{\text {reg }}(\mathrm{Fr} 1)$ and CD45RA-Fox$\mathrm{P} 3^{\text {high }}$ activated $\mathrm{T}_{\text {reg }}(\mathrm{Fr} 2)$, and activated $\mathrm{T}_{\text {eff }}$ were defined as CD45RA-FoxP3 ${ }^{\text {low }}$ T cells (Fr3) and CD45RA-FoxP3- T cells $(\mathrm{Fr} 4+5)$. In the present study, we found that both resting $\mathrm{T}_{\text {reg }}$ and activated $\mathrm{T}_{\text {reg }}$ were decreased, whereas CD45RA-FoxP3 $3{ }^{\text {low }}$ non- $\mathrm{T}_{\text {reg }}(\mathrm{Fr} 3)$ level was increased in patients with stable AP and old MI compared to controls, which is inconsistent with previous studies showing that peripheral $\mathrm{T}_{\text {reg }}$ is normal in these patients. ${ }^{14}$ Miyara et al showed that the CD45RA-FoxP3 ${ }^{\text {low }} \mathrm{T}$ cell (Fr3) population produces high amounts of pro-inflammatory cytokines such as IL- 2 and interferon- $\gamma$ (IFN- $\gamma$ ) and does not have suppressor function, indicating that this population does not seem to be real $\mathrm{T}_{\text {reg }}$ but $\mathrm{T}_{\text {eff. }}{ }^{17} \mathrm{Importantly}$, in the present study, further analysis by defining $\mathrm{T}_{\text {reg }}$ as $\mathrm{CD}^{+}{ }^{+} \mathrm{CD} 4{ }^{+} \mathrm{FoxP} 3^{+}$ cells, without staining CD45RA, showed that there was no dif-

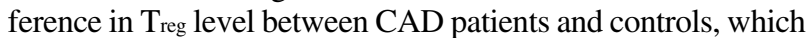
could be explained by the inappropriate inclusion of increased Teff Fr3 fraction in the Treg population. Therefore, the present analysis may be an ideal classification for $\mathrm{T}_{\text {reg }}$ to examine their role in human atherosclerotic disease. Discrepancy between the present findings and previous work with regards to the association between $\mathrm{T}_{\mathrm{reg}}$ level and coronary atherosclerosis may potentially be due to the difference in the definition of $T_{\text {reg. }}$.

It was shown that upon activation through $\mathrm{T}$ cell receptor, resting $\mathrm{T}_{\mathrm{reg}}(\mathrm{Fr} 1)$ have an ability to easily proliferate, become activated $\mathrm{T}_{\text {reg }}(\mathrm{Fr} 2)$, suppress $\mathrm{T}_{\text {eff, }}$ and undergo cell death. ${ }^{17}$ Although both resting $\mathrm{T}_{\text {reg }}$ and activated $\mathrm{T}_{\text {reg }}$ are shown to effectively suppress $T_{\text {eff }}$ response, the mechanisms underlying the suppression mediated by both $\mathrm{T}_{\text {reg }}$ types remain to be elucidated. The resting $T_{\text {reg }}$ population decreases with aging possibly due to decreased production in the thymus, whereas generation of activated $\mathrm{T}_{\text {reg }}$ in the periphery in aged individuals may compensate for the decreased $T_{\text {reg. }}$ In agreement with a previous study, ${ }^{17}$ the decrease of resting $\mathrm{T}_{\text {reg }}$ and the increase of activated $\mathrm{T}_{\text {reg }}$ with aging were observed in the control group (Figure 3). Similarly, resting $T_{\text {reg }}$ tended to decrease with aging in the CAD group, whereas activated $\mathrm{T}_{\text {reg }}$ was not increased but rather decreased. Notably, we found that the ex- pression of Treg activation markers such as CD25 or CTLA-4 was significantly upregulated in activated $\mathrm{T}_{\mathrm{reg}}$ of the CAD group compared to the control group, which may promote the death of this population. Taken together, we suppose that decreased activated $\mathrm{T}_{\text {reg }}$ in the CAD group might be due to the increased cell death after activation. Further studies are needed to identify the molecular mechanisms for the decrease in activated $T_{\text {reg }}$ in the CAD group.

Atherosclerosis is an inflammatory condition of the arterial wall involving innate and adaptive immunity. ${ }^{4}$ It is well recognized that serum hs-CRP concentration is one of the most popular and established inflammation markers and independently predicts future cardiovascular events, ${ }^{21}$ although its level may be easily changed by systemic inflammatory responses. Interestingly, we observed an inverse correlation between $\mathrm{T}_{\mathrm{reg}} / \mathrm{T}_{\mathrm{eff}}$ ratio and serum hs-CRP, suggesting that the $\mathrm{T}_{\text {reg/ }} / \mathrm{T}_{\text {eff }}$ ratio in the peripheral blood could be a useful marker to predict future cardiovascular events. In addition, because the distribution of $\mathrm{T}_{\text {reg/ }} / \mathrm{T}_{\text {eff }}$ ratio is diverse in patients with low serum hs-CRP, measurement of $\mathrm{T}_{\mathrm{reg}} / \mathrm{T}_{\text {eff }}$ ratio may enable more detailed evaluation of immune-inflammatory status in CAD patients in combination with hs-CRP.

The present study had some limitations that should be considered when interpreting the results. First, the number of patients was small, and so additional larger trials are needed to validate these observations. Second, we examined only peripheral blood samples, and analysis of the local immune response in atherosclerotic lesions was not performed. Given that $T_{\text {reg }}$ in circulation are reported to migrate into inflamed tissues to dampen local inflammation, ${ }^{22}$ the dynamics of $\mathrm{T}_{\text {reg localization should }}$ be examined to determine the clinical importance of $\mathrm{T}_{\text {reg }}$ in atherosclerosis. Finally, it remains unclear whether reduced $\mathrm{T}_{\mathrm{reg}} / \mathrm{T}_{\text {eff }}$ ratio is a cause or result of atherosclerotic disease.

\section{Conclusions}

Reduced $\mathrm{T}_{\mathrm{reg}} / \mathrm{T}_{\text {eff }}$ ratio is closely related with the pathophysiology of coronary atherosclerosis, suggesting that peripheral $\mathrm{T}_{\mathrm{reg}} / \mathrm{T}_{\mathrm{eff}}$ ratio may be a useful marker for the evaluation of severity of atherosclerosis. The present data imply that enhancing a $\mathrm{T}_{\mathrm{reg}}-$ mediated immune response could be a possible therapeutic approach to treat human atherosclerosis, although prospective clinical studies are required to ascertain whether reduced $\mathrm{T}_{\text {reg }}$ promotes atherosclerosis in humans.

\section{Acknowledgments}

The authors are grateful to Dr Katsuji Ikekubo and Tsutomu Kamino in Kenko Life Plaza, Hyogo Health Service Association for assistance in collecting control volunteer data, and to Naoki Kitano for critical reading of the manuscript.

\section{Disclosures}

The authors have no conflicts of interest to declare.

\section{Funding Sources}

This work was supported by JSPS KAKENHI Grant Numbers 25860601 (N.S.) and 24591114 (T.Y.), a Japan Heart Foundation and Astellas/Pfizer Grant for Research on Atherosclerosis Update (N.S.), Kimura Memorial Heart Foundation Research Grant for 2011 (N.S.), Japan Heart Foundation/ Novartis Grant for Research Award on Molecular and Cellular Cardiology 2012 (N.S.), a Translational Research Grant from Japan Circulation Society (K.H.), and research grants from Banyu Life Science Foundation International (N.S.), Suzuken Memorial Foundation (N.S. and T.Y.), ONO Medical Research Foundation (N.S.), Takeda Science Foundation (N.S. and T.Y.), Uehara Medical Foundation (T.Y., K.H.), Mochida Memorial Foundation (T.Y.), Mitsui Life Social Welfare Foundation (T.Y.), Kanae Medical Foundation (N.S., T.Y.), Senshin Medical Research Foundation (T.Y.), and Yakult Bioscience Research Foundation (T.Y.). 


\section{References}

1. Ross R. Atherosclerosis: An inflammatory disease. N Engl J Med 1999 340: $115-126$.

2. Libby P. Mechanisms of acute coronary syndromes and their implications for therapy. N Engl J Med 2013; 368: 2004-2013.

3. Simon DI. Inflammation and vascular injury: Basic discovery to drug development. Circ J 2012; 76: 1811-1818.

4. Hansson GK, Hermansson A. The immune system in atherosclerosis Nat Immunol 2011; 12: 204-212.

5. Ozaki Y, Imanishi T, Taruya A, Aoki H, Masuno T, Shiono Y, et al. Circulating $\mathrm{CD} 14^{+} \mathrm{CD} 16^{+}$monocyte subsets as biomarkers of the severity of coronary artery disease in patients with stable angina pectoris. Circ J 2012; 76: 2412-2418.

6. Ait-Oufella H, Salomon BL, Potteaux S, Robertson AK, Gourdy P, Zoll J, et al. Natural regulatory T cells control the development of atherosclerosis in mice. Nat Med 2006; 12: 178-180.

7. Sasaki N, Yamashita T, Takeda M, Shinohara M, Nakajima K, Tawa $\mathrm{H}$, et al. Oral anti-CD3 antibody treatment induces regulatory $\mathrm{T}$ cells and inhibits the development of atherosclerosis in mice. Circulation 2009; 120: 1996-2005

8. Takeda M, Yamashita T, Sasaki N, Nakajima K, Kita T, Shinohara $\mathrm{M}$, et al. Oral administration of an active form of vitamin D3 (calcitriol) decreases atherosclerosis in mice by inducing regulatory $\mathrm{T}$ cells and immature dendritic cells with tolerogenic functions. Arterioscler Thromb Vasc Biol 2010; 30: 2495-2503.

9. Klingenberg R, Gerdes N, Badeau RM, Gistera A, Strodthoff D, Ketelhuth DF, et al. Depletion of FOXP3+ regulatory T cells promotes hypercholesterolemia and atherosclerosis. J Clin Invest 2013; 123: $1323-1334$

10. Kita T, Yamashita T, Sasaki N, Kasahara K, Sasaki Y, Yodoi K, et al. Regression of atherosclerosis with anti-CD3 antibody via augmenting a regulatory T-cell response in mice. Cardiovasc Res 2014; 102: $107-117$.

11. Sasaki N, Yamashita T, Takeda M, Hirata K. Regulatory T cells in atherogenesis. J Atheroscler Thromb 2012; 19: 503-515.

12. Kasahara K, Sasaki N, Yamashita T, Kita T, Yodoi K, Sasaki Y, et al. CD3 antibody and IL-2 complex combination therapy inhibits atherosclerosis by augmenting a regulatory immune response. $J \mathrm{Am}$ Heart Assoc 2014; 3: e000719, doi:10.1161/JAHA.113.000719.

13. Mor A, Luboshits G, Planer D, Keren G, George J. Altered status of $\mathrm{CD} 4(+) \mathrm{CD} 25(+)$ regulatory $\mathrm{T}$ cells in patients with acute coronary syndromes. Eur Heart J 2006; 27: 2530-2537.

14. Ammirati E, Cianflone D, Banfi M, Vecchio V, Palini A, De Metrio $\mathrm{M}$, et al. Circulating CD4+CD25hiCD127lo regulatory T-cell levels do not reflect the extent or severity of carotid and coronary atherosclerosis. Arterioscler Thromb Vasc Biol 2010; 30: 1832-1841.

15. Wigren M, Bjorkbacka H, Andersson L, Ljungcrantz I, Fredrikson GN, Persson M, et al. Low levels of circulating CD4+FoxP3+ T cells are associated with an increased risk for development of myocardial infarction but not for stroke. Arterioscler Thromb Vasc Biol 2012; 32: 2000-2004.

16. Sakaguchi S, Yamaguchi T, Nomura T, Ono M. Regulatory T cells and immune tolerance. Cell 2008; 133: 775-787.

17. Miyara M, Yoshioka Y, Kitoh A, Shima T, Wing K, Niwa A, et al. Functional delineation and differentiation dynamics of human CD4+ $\mathrm{T}$ cells expressing the FoxP3 transcription factor. Immunity 2009; 30: 899-911.

18. Liuzzo G, Biasucci LM, Trotta G, Brugaletta S, Pinnelli M, Digianuario $\mathrm{G}$, et al. Unusual CD4+CD28null T lymphocytes and recurrence of acute coronary events. J Am Coll Cardiol 2007; 50: 1450-1458.

19. Giubilato S, Liuzzo G, Brugaletta S, Pitocco D, Graziani F, Smaldone $\mathrm{C}$, et al. Expansion of CD4+CD28null T-lymphocytes in diabetic patients: Exploring new pathogenetic mechanisms of increased cardiovascular risk in diabetes mellitus. Eur Heart J 2011; 32: $1214-$ 1226.

20. Dietel B, Cicha I, Voskens CJ, Verhoeven E, Achenbach S, Garlichs $\mathrm{CD}$. Decreased numbers of regulatory $\mathrm{T}$ cells are associated with human atherosclerotic lesion vulnerability and inversely correlate with infiltrated mature dendritic cells. Atherosclerosis 2013; 230: 92-99.

21. Libby P, Ridker PM, Maseri A. Inflammation and atherosclerosis. Circulation 2002; 105: 1135-1143.

22. Maganto-Garcia E, Tarrio ML, Grabie N, Bu DX, Lichtman AH. Dynamic changes in regulatory $\mathrm{T}$ cells are linked to levels of dietinduced hypercholesterolemia. Circulation 2011; 124: 185-195. 